\title{
Baseline and metoclopramide induced plasma prolactin level in lean PCOS women according to their FAI phenotype
}

\author{
S. Mrozinska ${ }^{1}$, T. Milewicz², M. Kiałka², M. Krzyczkowska-Sendrakowska ${ }^{2}$, A. Przywara ${ }^{3}$, J. Guzik
}

${ }^{1}$ Department of Metabolic Diseases, Jagiellonian University, Medical College, Cracow, Poland

2Department of Gynecological Endocrinology, Jagiellonian University, Medical College, Cracow, Poland

${ }^{3}$ Provincial Specialist Hospital, Rybnik, Poland

${ }^{4}$ St. Raphael Hospital, Cracow, Poland

\section{Objectives:}

The aim of our study was to compare: the baseline and metoclopramide induced prolactin plasma level between women with polycystic ovary syndrome $(\mathrm{PCOS})$ with FAI $<5$ phenotype (group A) and PCOS women with FAI $>$ 5 phenotype (group B).

(FAI, total testosterone divided by sex hormone biding globulin, whole multiply by 100 )

\section{Methods:}

The study population consisted of 354 lean women with PCOS.

In all the patients the prolactin level at 2 a.m., 8 a.m. and during the metoclopramide oral test, were assessed. The free androgen index was calculated to each woman.

The population was dived into two group according to the FAI phenotype. The group A contains 250 women with PCOS and FAI $>5$, the group B contains 104 women with PCOS and FAI $<5$. The groups did not differ in age (group A: $24.3 \pm 5.3$ years vs. group B $25.4 \pm 5.7$ years and in BMI (group A: $21.3 \pm 2.1 \mathrm{~kg} / \mathrm{m}^{2}$ vs. group B: $20.9 \pm 2.1$ $\mathrm{kg} / \mathrm{m} 2)$ at baseline.

\begin{tabular}{|c|c|c|c|}
\hline Parameter & Phenotypes with FAl > 5 & Phenotypes with FAl $<5$ & P -value \\
\hline PRL 08.00 am $(\mu \mathrm{lU} / \mathrm{ml})$ & $55.2 \pm 94.2$ & $98.7 \pm 131.5$ & $<0.001$ \\
\hline PRL 02.00 am $(\mu \mathrm{lU} / \mathrm{ml})$ & $159.8 \pm 297.8$ & $390.2 \pm 335.1$ & $<0.001$ \\
\hline PRL 60 min $(\mu l \mathrm{l} / \mathrm{ml})$ & $690.41 \pm 1401.4$ & $1853.5 \pm 2646.4$ & $<0.001$ \\
\hline PRL 120 min $(\mu l \mathrm{U} / \mathrm{ml})$ & $606.4 \pm 1210.6$ & $1328.2 \pm 1790.9$ & $<0.001$ \\
\hline PRL 60min /PRL 0 min $(\mu \mathrm{lU} / \mathrm{ml})$ & $14.3 \pm 9.6$ & $19.1 \pm 13.0$ & $<0.001$ \\
\hline PRL 120min /PRL 0 min $(\mu l U / m l)$ & $11.1 \pm 6.5$ & $14.7 \pm 10.2$ & $<0.001$ \\
\hline PRL $60 \mathrm{~min} / 120 \mathrm{~min}(\mu \mathrm{lU} / \mathrm{ml})$ & $1.41 \pm 1.3$ & $1.54 \pm 1.8$ & NS \\
\hline PRL $120 \min / 60 \min (\mu \mathrm{lU} / \mathrm{ml})$ & $1.3 \pm 2.5$ & $1.0 \pm 1.5$ & NS \\
\hline
\end{tabular}

\section{Results:}

The prolactin level was statistically significant higher $(\mathrm{p}<0.0001)$ in group B at 2 a.m. (55.2 uIU/ml vs. 98.7 uIU/ml), at 8 a.m. (159.8 uIU/ml vs. $390.2 \mathrm{uIU} / \mathrm{ml})$, at 60-minute of metoclopramide test $(690.41 \mathrm{uIU} / \mathrm{ml} \mathrm{vs}$. $1853.5 \mathrm{uIU} / \mathrm{ml})$ and at 120-minute of metoclopramide test $(606.4 \mathrm{uIU} / \mathrm{ml} \mathrm{vs} .1328 .2 \mathrm{uIU} / \mathrm{ml})$. The prolactin ratio at 120 -minute of metoclopramide test to the baseline level was also higher in the group B (11.1 \pm 6.5 vs. $14.7 \pm 10.2$; $\mathrm{p}<0.001)$.

Conclusions:

The results may suggest that prolactin levels are lower in women with PCOS and FAI $>5$ than in women with PCOS and FAI $<5$. The prolactin level in PCOS women may be connected with the level of androgenicity in PCOS women. 